8] McKie PM, Cataliotti A, Lahr BD, et al. The prognostic value of N-terminal pro-B-type natriuretic peptide for death and CV events in healthy normal and stage $\mathrm{A} / \mathrm{B}$ heart failure subjects. J Am Coll Cardiol 2010;55:2140-7.
[9] Gupta S, Rohatgi A, Ayers CR, et al. Risk scores versus natriuretic peptides for identifying prevalent stage B heart failure. Am Heart J 2011;161:923-30.

\title{
The relevance of the brain in the diseased heart: Authors' response
}

\author{
Vitor Hugo Pereira ${ }^{\mathrm{a}, \mathrm{b}, \mathrm{c}}$, João José Cerqueira ${ }^{\mathrm{a}, \mathrm{b}}$, Joana Almeida Palha ${ }^{\mathrm{a}, \mathrm{b}}$, Nuno Sousa ${ }^{\mathrm{a}, \mathrm{b}, *}$ \\ ${ }^{a}$ Life and Health Sciences Research Institute (ICVS), School of Health Sciences, University of Minho, Braga, Portugal \\ b ICVS/3B's-PT Government Associate Laboratory, Braga, Guimarães, Portugal \\ c Cardiology Department, Centro Hospitalar do Alto Ave, Guimarães, Portugal
}

\section{A R T I C L E I N F O}

\section{Article history:}

Received 21 July 2013

Accepted 25 July 2013

Available online 2 August 2013

\section{Keywords:}

Cardiovascular diseases

Circadian rhythm

Melatonin

Cortisol

\section{To the Editor:}

In their comment to our recent paper entitled "Stressed Brain, Diseases Heart: A review on the pathophysiologic mechanisms of neurocardiology." [1], Dominguez-Rodriguez and Abreu-Gonzalez [2] emphasize the relevance of circadian rhythm in cardiovascular diseases and propose the suprachiasmatic nucleus and melatonin as key mediators in its pathophysiology. We found this a very interesting observation. The incidence of acute myocardial infarction [3] and its extension [4] displays a circadian pattern usually peaking in early morning. Whether this is a consequence of the oscillating levels of circulating hormones or from a direct action of central mechanisms on the heart and vessels themselves is still a matter of dispute.

In addition to melatonin, also cortisol has been implicated in the circadian variation of cardiovascular diseases. Cortisol is produced by the adrenal glands following a circadian pattern with the zenith $1 \mathrm{~h}$ before awakening. Interestingly, there is evidence that more relevant than the levels of cortisol at peaks, is the sustained elevation of cortisol (measured in the hair and reflecting the accumulated circulating levels in the previous three months), that has been associated with a significant risk of cardiovascular events [5]. In fact, in a cohort of 4047 patients from the Whitehall II study, Kumari and colleagues showed that flatter slopes in cortisol decline across the day, but not peak morning cortisol levels, were associated with increased risk of all-cause and cardiovascular mortality in a follow-up period of 6 years [6]. In addition, in a recent pilot study, we observed that higher blood cortisol levels at admission to a cardiac care unit

* Corresponding author at: Instituto de Ciencias da Vida e da Saude (ICVS), Campus de Gualtar, Universidade do Minho, 4710-057 Braga, Portugal. Tel.: +351 253604806.

E-mail address: njcsousa@ecsaude.uminho.pt (N. Sousa). were related with a worst outcome during the in-hospital stay regarding left ventricular function and Killip class (Pereira et al., Poster Presentation, Heart Failure 2013). These observations suggest that higher levels of cortisol are associated with worst cardiovascular outcome at the long-term, but fail to demonstrate a direct association between peak levels of cortisol and acute events; this brings to scene the possible role of other mediators in the circadian variation of cardiovascular diseases, which may well include melatonin.

Finally it is interesting to note the relation between stress and the disruption of global circadianism. Chronic stress disturbs the normal circadian rhythm, altering the normal variation of both cortisol [7] and melatonin [8], and directly impairing pineal sympathetic inputs [8], which may well contribute to the increased risk of cardiovascular diseases in patients under chronic psychological stress. The effects of chronic stress in the suprachiasmatic nucleus need to be investigated in greater detail. Highlighting these poorly studied aspects and relating what may seem disperse evidence, will certainly pave the way of neurocardiology and further studies, both at basic and clinical levels, and will be critical to clarify the role of circadian clock regulators in the incidence and natural history of cardiovascular events.

The authors of this manuscript have certified that they comply with the Principles of Ethical Publishing in the International Journal of Cardiology.

\section{References}

1] Pereira VH, Cerqueira JJ, Palha JA, Sousa N. Stressed brain, diseased heart: a review on the pathophysiologic mechanisms of neurocardiology. Int J Cardiol 2013;166(1):30-7.

2] Dominguez-Rodriguez A, Abreu-Gonzalez P. The relevance of the brain in the diseased heart: role of the suprachiasmatic nucleus. Int J Cardiol 2013 Jul 17, http://dx.doi.org/ 10.1016/j.jjcard.2013.06.136.

[3] Reavey M, Saner H, Paccaud F, Marques-Vidal P. Exploring the periodicity of cardiovascular events in Switzerland: variation in deaths and hospitalizations across seasons, day of the week and hour of the day. Int J Cardiol 2013 Oct 3;168(3):2195-200.

[4] Suárez-Barrientos A López-Romero P, Vivas D, et al. Circadian variations of infarct size in acute myocardial infarction. Heart 2011;97(12):970-6.

[5] Manenschijn L, Schaap L, van Schoor NM, et al. High long-term cortisol levels, measured in scalp hair, are associated with a history of cardiovascular disease. J Clin Endocrinol Metab 2013;98(5):2078-83.

[6] Kumari M, Shipley M, Stafford M, Kivimaki M. Association of diurnal patterns in salivary cortisol with all-cause and cardiovascular mortality: findings from the Whitehall II study. J Clin Endocrinol Metab 2011;96(5):1478-85.

[7] Sousa N, Almeida OF. Disconnection and reconnection: the morphological basis of (mal) adaptation to stress. Trends Neurosci 2012;35(12):742-51.

[8] Dagnino-Subiabre A, Orellana JA, Carmona-Fontaine C, et al. Chronic stress decreases the expression of sympathetic markers in the pineal gland and increases plasma melatonin concentration in rats. J Neurochem 2006;97(5):1279-87. 